\title{
Pharmaco-economics Study: A cost variation analysis of various statin preparations available in Nepali market
}

\author{
Sirisa Karki*, Gita Paudel, Karma Murti Bhurtyal \\ Department of Pharmacology, Chitwan Medical College, Bharatpur-5, Chitwan, Nepal
}

\begin{abstract}
BACKGROUND

This work is licensed under a Creative Commons Attribution 4.0 Unported License.

Hyperlipidemia is one of the greatest risk factors contributing to prevalence and severity of cardiovascular diseases. Treatment of hyperlipidemia with statins have proven efficacy in reduction of cardiovascular events. In the present study, we aim to find out the variation in cost of commercially available statin products in Nepal.
\end{abstract}

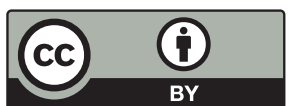

\section{METHODS}

The price of different statin products with same formulation and strength was obtained from various medicine importers and distributors inside Kathmandu valley, Pokhara and Chitwan. Percentage of cost variation and cost ratio was calculated.

\section{RESULTS}

High percentage of cost variation was observed among Indian product with Atorvastatin $10 \mathrm{mg}$ (898.8\% Cost ratio: 9.98) followed by Atorvastatin $20 \mathrm{mg}$ (894.52\% Cost ratio: 9.94). Least percentage of cost variation was observed with Nepal manufactured Atorvastatin $5 \mathrm{mg}$ (49.62 Cost ratio: 1.49).

\section{CONCLUSION}

There is a wide percentage of cost variation with available statins in the Nepali market. Regulation of drug price by concerned agencies and by government should be a national priority. Rational drug prescription with low cost is important for treatment adherence and disease outcome

\section{KEYWORDS}

cost ratio, hyperlipidemia, percentage cost variation, statins

\section{INTRODUCTION}

Cardiovascular diseases (CVD) are a group of disorders of the heart and blood vessels which includes acute events like heart attack and strokes accounting for over $43 \%$ of all global deaths from Non-Communicable Diseases (NVDs). Increased blood pressure, raised blood glucose, raised blood lipid levels, and obesity owing to unhealthy diet and physical inactivity predisposes CVD. In Nepal, the actual burden and trend of CVD is unknown because of lack of enough screening and studies, however, various studies indicate that the problem is common and the incidence is on the rise. 1,2

WHO has included blood sugar and lipid levels as independent predictors of CVD.3 Dyslipidemia characterized by elevated blood level of plasma lipids which includes triglycerides (TG), cholesterol, phospholipids, and or plasma lipoproteins namely very-low-density-lipoproteins (VLDL), low-densitylipoproteins (LDL) along with decreased level of high-density lipoproteins (HDL) has been found to be the most prevalent cardiovascular risk factor. 1, 4 Lipid lowering drugs in recent years have significantly contributed to improvement of CVD therapy. A variety of lipid lowering agents are available in the market and their prescription usually depends on the patient's lipid profile, cardiovascular risks and other comorbid conditions dictated by guidelines. 5 Statins also known as HMG CoA reductase inhibitors have been the cornerstone of treatment for hyperlipidemia and has been associated with a reduction of heart attack, stroke and peripheral arterial disease. 6 Atorvastatin has been included in the WHO list of essential medicines but its availability in Nepal has been labelled poor by WHO.7 In the present study we plan to find out the variation in cost of commercially available Nepali and international -statin products in Nepal and to evaluate the difference in cost of various brands of same statins by calculating the percentage variation in cost in Nepali Rupees (NRS).

*Corresponding Author | Sirisa Karki, Department of Pharmacology, Chitwan Medical College, Bharatpur-5, Kailashnagar, Chitwan, Nepal | Email: karki.sirisa@cmc.edu.np 


\section{METHODS}

Ethical approval for the study was obtained from Chitwan Medical College, Institutional review Committee (CMC-IRC). A list of commercially available domestic and internationally produced statins approved by department of drug administration (DDA) for sale in Nepal was obtained from the DDA office in Bijulibazar, Kathmandu, Nepal. The price of different statin preparations was obtained from various medicine importers and distributors inside Kathmandu valley, Pokhara and Chitwan. The price of the drug was calculated per 10 tablets or capsules in Nepali Rupees. A unique drug formulation or dosage manufactured by only one company and combination drugs were excluded from the analysis. We noted the maximum and minimum price of a particular statin manufactured by various pharmaceutical companies in the same strength. The cost was also checked at retail drug store. The cost ratio of a statin was calculated using the following formula: Cost Ratio = Expensive drug/Cheapest drug. It indicates the number of times an expensive drug is costlier than its cheapest counterpart. Also, percentage cost variation was calculated using the following formula: $\%$ Cost variation $=($ maximum cost - minimum cost $) /$ minimum cost $X 100$

\section{RESULTS}

Among the 78 pharmaceutical companies registered with DDA, 18 produce statins. Only atorvastatin and rosuvastatin were being produced in Nepal. Percentage variation in cost was found to be atorvastatin (20mg): $185.58 \%$, rosuvastatin (10mg): $211.76 \%$ among Nepali products and atorvastatin (10mg): $898.80 \%$, rosuvastatin (10mg): $211.76 \%$ among Indian products (Table 1 and 2).

Table 1. Variation in cost of statins manufactured in Nepal

\section{DISCUSSION}

Medicines account for $20-60 \%$ of health spending in low- and middle- income countries with up to $90 \%$ of the population purchasing medicine out-of-pocket payments making medicine the largest family expenditure item after food. An estimated more than 5 days wage for a month of statin prescription has been reported in Nepal. Medicines with higher costs may be unaffordable for a majority of population living in the low- and middle- economic countries and is also a major burden on government budgets. 7, 8 The general concept of Nepalese population regarding expensive items being better and medicine being an essential commodity could add to the financial burden of the family. A wide-variation in the prices of different brands of same formulations has massive ecnomic influence in the genreal population. Also, prescribing any brand is entirely physician-dependent who may not consider the socioeconomic status of the patients rather aiming towards personal interest.9 Thus, prescribing physisicians could play an important role in reducing the economic burden to the family if such type of drug picing studies were available. Nonetheless, practicing physician should not avoid treating a patient with a particular drug because it is expensive, rather balance therapeutic decisions. 10

There was a low percentage cost variation among Nepali products compared to Indian products. It could be because the cost of production, marketing and promotion strategies of Nepali company being same. Nepali products were cheaper compared to Indian product except atorvastatin 5 and $10 \mathrm{mg}$ tablets.

The pricing of any drug manufactured in Nepal is regulated

\begin{tabular}{|l|l|l|l|l|l|}
\hline Drug & Dose & Minimum Cost (NPR) & Maximum Cost (NPR) & Cost Ratio & \% Cost variation \\
\hline Atorvastatin & $5 \mathrm{mg}$ & 6.75 & 10.1 & 1.49 & 49.62 \\
\hline & $10 \mathrm{mg}$ & 10.7 & 16.12 & 1.50 & 50.65 \\
\hline & $20 \mathrm{mg}$ & 10.75 & 30.7 & 2.85 & 185.58 \\
\hline & $40 \mathrm{mg}$ & 15 & 37 & 2.46 & 146.66 \\
\hline Rosuvastatin & $5 \mathrm{mg}$ & 11 & 16.5 & 1.5 & 50 \\
\hline & $10 \mathrm{mg}$ & 17 & 53 & 3.11 & 211.76 \\
\hline & $20 \mathrm{mg}$ & 27 & 72.84 & 2.69 & 169.77 \\
\hline
\end{tabular}

Table 2. Variation in cost of statins manufactured in India

\begin{tabular}{|l|l|l|l|l|l|}
\hline Drug & Dose & Minimum Cost (NPR) & Maximum Cost (NPR) & Cost Ratio & \% Cost variation \\
\hline Atorvastatin & $5 \mathrm{mg}$ & 6.75 & 20.25 & 3 & 200 \\
\hline & $10 \mathrm{mg}$ & 3.34 & 33.36 & 9.98 & 898.80 \\
\hline & $20 \mathrm{mg}$ & 6.21 & 61.76 & 9.94 & 894.52 \\
\hline & $40 \mathrm{mg}$ & 22.5 & 79.04 & 3.51 & 251.28 \\
\hline Rosuvastatin & $5 \mathrm{mg}$ & 12.1 & 50.65 & 4.18 & 318.59 \\
\hline & $10 \mathrm{mg}$ & 15.18 & 88.5 & 5.83 & 483.00 \\
\hline & $20 \mathrm{mg}$ & 35 & 59 & 1.68 & 68.57 \\
\hline
\end{tabular}


by DDA. The price of a drug produced by a pharmaceutical company depends on the cost of active pharmaceutical ingredient (API), its transport, manufacturing of the drug, operational costs, marketing and promotion strategies.9 This could be the reason behind the discrepency in price. However, in Nepal the price variation is entirely due to marketing, promotion and operational costs.

Among statins, only atorvastatin and rosuvastatin were being produced by privately owned pharmaceutical companies in Nepal. Statins are second to none 11 and manufacturing all of it could prove injudicious to profit generating tendency of private pharmaceuticals companies. We can also infer that atorvastatin and rosuvastatin are the most commonly prescribed drugs in Nepal, however further study needs to be conducted to draw such a conclusion.

Atorvastatin is the only statin listed in the national list of essential medicines 12 and is distributed for free at government health facilities but its availability is poor.7 Rosuvastatin has been recently added to the National Drug Formulary. 13 Its availability is yet to be studied.

\section{CONCLUSION}

In this present study we highlighted the wide variation in cost of different statins available in Nepal. The government of Nepal should take active measures to maintain uniformity in price of essential drugs including statins ensuring easy availability and affordibility. Prescribing physisicans should be aware regarding formulations with cost variations available in the market. Rational precription of low cost drugs could help improve drug adherence and disease outcome.

\section{CONFLICT OF INTEREST: NONE}

\section{FUNDING: NA}

\section{REFERENCES}

1. Dhungana RR, Thapa P, Devkota S, Banik PC, Gurung Y, Mumu SJ, et al. Prevalence of cardiovascular disease risk factors: A community-based cross-sectional study in a peri-urban community of Kathmandu, Nepal. Indian heart journal. 2018;70 Suppl 3:S20-s27. http://dx.doi.org/10.1016/j.hj.2018.03.003

2. Bhandari GP, Angdembe MR, Dhimal M, Neupane S, Bhusal C. State of non-communicable diseases in Nepal. BMC Public Health. 2014;14:23. http://dx.doi.org/10.1186/1471-2458-1423

3. World Health Organization cardiovascular disease risk charts: revised models to estimate risk in 21 global regions. The Lancet Global health. 2019;7:e1332-e45. http://dx.doi.org/10.1016/ s2214-109x(19)30318-3

4. Limbu YR, Rai SK, Ono BK, Kurokawa M, Yanagida JI, Rai G, et al. Lipid profile of adult Nepalese population. Nepal Med Coll J 2008; 10:4-7
5. Grundy SM, Stone NJ, Bailey AL, Beam C, Birtcher KK, Blumenthal RS, et al. 2018 AHA/ACC/AACVPR/AAPA/ ABC/ACPM/ADA/AGS/APhA/ASPC/NLA/PCNA Guideline on the Management of Blood Cholesterol. A Report of the American College of Cardiology/American Heart Association Task Force on Clinical Practice Guidelines. 2019;73:e285-e350. http://dx.doi.org/10.1016/j.jacc.2018.11.003

6. Last AR, Ference JD, Menzel ER. Hyperlipidemia: Drugs for Cardiovascular Risk Reduction in Adults. Am Fam Physician. 2017;95:78-87

7. Mendis S, Fukino K, Cameron A, Laing R, Filipe A, Jr., Khatib $O$, et al. The availability and affordability of selected essential medicines for chronic diseases in six low- and middle-income countries. Bull World Health Organ. 2007;85:279-88. http:// dx.doi.org/10.2471/blt.06.033647

8. WHO Guideline on Country Pharmaceutical Pricing Policies [Internet]. Geneva: World Health Organization; 2015 [cited 2020 3rd February 2020]. Available from: www.who.int/about/ licensing/copyright_form/en/index.html.

9. Davari M, Khorasani E, Tigabu BM. Factors Influencing Prescribing Decisions of Physicians: A Review. Ethiop J Health Sci. 2018;28:795-804. http://dx.doi.org/10.4314/ejhs.v28i6.15

10. Chawan VS, Gawand KV, SV. B. Cost analysis of oral hypolipidemic agents available in India. International Journal of Basic \& Clinical Pharmacology. 2014:954. http://dx.doi. org/10.5455/2319-2003.ijbcp20141234

11. John LJ, Esheiba EM, Fathi MAM, Agarwal AK, Sreedharan J, Muttappallymyalil J, et al. Efficacy of Statins in Dyslipidemia: A Non interventional comparative study in a tertiary care hospital, Ajman, UAE. Nepal Journal of Epidemiology. 2014;4:428-32. http://dx.doi.org/https://doi.org/10.3126/nje.v4i5.12023

12. DDA. National List of Essential Medicines- Nepal. 4th Revision. Kathmandu: Government of Nepal; 2009.

13. Nepalese National Formulary. 3rd ed. Kathmandu: Department of Drug Administration; 2018. p. 81-92. 